\title{
Involvement of Brain-Derived Neurotrophic Factor in Spatial Memory Formation and Maintenance in a Radial Arm Maze Test in Rats
}

\author{
Makoto Mizuno,, ${ }^{1}$ Kiyofumi Yamada, ${ }^{1}$ Ana Olariu, ${ }^{1}$ Hiroyuki Nawa, ${ }^{2}$ and Toshitaka Nabeshima $^{1}$ \\ ${ }^{1}$ Department of Neuropsychopharmacology and Hospital Pharmacy, Nagoya University Graduate School of Medicine, \\ Showa-ku Nagoya 466-8560, Japan, and 2Department of Molecular Neurobiology, Brain Research Institute, Niigata \\ University, Niigata 951-8585, Japan
}

Brain-derived neurotrophic factor (BDNF) regulates both shortterm synaptic functions and activity-dependent synaptic plasticity such as long-term potentiation. In the present study, we investigated the role of BDNF in the spatial reference and working memory in a radial arm maze test. The radial arm maze training resulted in a significant increase in the BDNF mRNA expression in the hippocampus, although the expression in the frontal cortex did not change. When spatial learning was inhibited by treatment with 7-nitroindazole, an inhibitor of brain nitric oxide synthase, the increase in the hippocampal BDNF mRNA did not occur. To clarify the causal relation between BDNF mRNA expression and spatial memory formation, we examined the effects of antisense BDNF treatment on spatial learning and memory. A continuous intracerebroventricular infusion of antisense BDNF oligonucleotide resulted in an impairment of spatial learning, although the sense oligonucleotide had no effect. Treatment with antisense, but not sense, BDNF oligonucleotide was associated with a significant reduction of BDNF mRNA and protein levels in the hippocampus. Furthermore, treatment with antisense BDNF oligonucleotide in rats, which had previously acquired spatial memory by an extensive training, impaired both reference and working memory. There were no differences in locomotor activity, food consumption, and body weight between the antisense and sense oligonucleotide-treated rats. These results suggest that BDNF plays an important role not only in the formation, but also in the retention and/or recall, of spatial memory.

Key words: BDNF; working memory; reference memory; radial arm maze; antisense oligonucleotide; LTP; hippocampus
Brain-derived neurotrophic factor (BDNF) is a member of the neurotrophin family, which plays important roles in the survival, maintenance, and growth of neurons (Barde et al., 1982; Leibrock et al., 1989). BDNF supports the survival of many types of neurons, including mesencephalic dopaminergic neurons (Knüsel et al., 1991), septal cholinergic neurons (Nonner et al., 1996), and striatal GABAergic neurons (Ventimiglia et al., 1995). This neurotrophin influences the development of patterned connections (Cabelli et al., 1995) and growth and complexity of dendrites in the cerebral cortex (McAllister et al., 1995).

BDNF is also implicated in the modulation of synaptic transmission. Regarding the short-term synaptic function, BDNF enhances synaptic transmission (Lohof et al., 1993; Lessmann et al., 1994; Levine et al., 1995; Kang and Schuman, 1995, 1996), increases phosphorylation of subunits of NMDA receptors (Suen et al., 1997; Lin et al., 1998), and facilitates acetylcholine release (Knipper et al., 1994). In activity-dependent synaptic plasticity, BDNF enhances long-term potentiation (LTP) in the hippocampus (Figurov et al., 1996) but blocks the induction of long-term depression (LTD) in the visual cortex (Kinoshita et al., 1999). High-frequency stimulation, which induces LTP, increases BDNF mRNA in hippocampal slices (Patterson et al., 1992). In BDNF mutant mice, LTP is impaired, but the changes were restored by either adenovirus-mediated re-expression (Korte et al., 1995) or by the bath application of BDNF (Patterson et al., 1996).

Because LTP is considered a potential cellular mechanism un-

Received April 4, 2000; revised July 3, 2000; accepted July 6, 2000.

This work was supported in part by Grant-in-Aid for Science Research (number 12670085), a COE Grant from the Ministry of Education, Science, Sports, and Culture of Japan, and grants from the Research Foundation for Pharmacological Study and the Japan Society for the Promotion of Science (RFTF-96L00203).

Correspondence should be addressed to Dr. T. Nabeshima, Department of Neuropsychopharmacology and Hospital Pharmacy, Nagoya University Graduate School of Medicine, Showa-ku Nagoya 466-8560, Japan. E-mail: tnabeshi@med.nagoya-u.ac.jp. Copyright (C) 2000 Society for Neuroscience $0270-6474 / 00 / 207116-06 \$ 15.00 / 0$ derlying learning and memory, BDNF may be involved in memory processes The water maze learning was impaired in BDNF mutant mice (Linnarsson et al., 1997) or in rats that had received an intracerebroventricular inf usion of anti-BDNF antibody (Mu et al., 1999). A relation between BDNF mRNA expression and memory was shown in the passive avoidance test (Ma et al., 1998) and in the water maze test (Kesslak et al., 1998). It should be noted, however, that the behavioral tests used so far to investigate the role of BDNF in learning and memory are negatively motivated stressful paradigms and that various stresses and sensory stimulation affect BDNF expression (Ernfors et al., 1991; Nibuya et al., 1995; Smith et al., 1995).

Nitric oxide (NO) is a free radical gas with a role in synaptic plasticity, including learning and memory (Garthwaite and Boulton, 1995; Yamada and Nabeshima, 1998). A brain NO synthase (NOS) inhibitor 7-nitroindazole (7-NI) inhibited the spatial learning of rats (Zou et al., 1998a). Notably, Xiong et al. (1999) have demonstrated a mutual regulation of $\mathrm{NO}$ and BDNF synthesis in vitro and in vivo.

In the present study, we investigated the role of BDNF in learning and memory using a less stressful eight-arm radial arm maze test. We examined whether spatial memory formation is associated with changes in the level of BDNF mRNA in the brain. We also studied the changes in BDNF mRNA level when spatial learning is inhibited by treatment with 7-NI. Furthermore, to clarify the causal relation between BDNF expression and memory formation, we investigated the effects of BDNF antisense treatment on spatial learning and memory.

\section{MATERIALS AND METHODS}

Materials. Male Wistar rats (7-weeks-old; Charles River Japan, Yokohama, Japan) weighing $230 \pm 10 \mathrm{gm}$ at the beginning of experiments were used in the study. They were housed three per cage with ad libitum access to food and water under controlled laboratory conditions (a $12 \mathrm{hr}$ light/dark cycle with lights on at 9:00 A.M., $23 \pm 0.5^{\circ} \mathrm{C}, 50 \pm 0.5 \%$ humidity). 7 -NI was purchased from Lancaster Synthesis (Lancashire, UK). All experi- 
ments were performed in accordance with the Guidelines for Animal Experiments of the Nagoya University School of Medicine, the Guiding Principles for the Care and Use of Laboratory Animals approved by the Japanese Pharmacological Society, and the United States National Institutes of Health Guide for the Care and Use of Laboratory Animals.

Radial arm maze task. The radial arm maze used in the present study consisted of eight arms, numbered from 1 to $8(48 \times 12 \mathrm{~cm})$, extending radially from a central area $(32 \mathrm{~cm}$ in diameter), with a $5 \mathrm{~cm}$ edge around the apparatus. The training procedure was essentially the same as described previously (Zou et al., 1998a, 1999). Briefly, each animal was placed individually in the center of the maze and subjected to a reference and working memory task for $28 \mathrm{~d}$, where the same four arms (numbers 1 , 2,4 , and 7) were baited for each daily training trial. The other four arms (numbers 3, 5, 6, and 8) were never baited. The training trial continued until all four baits in the food cups had been consumed or until 5 min had elapsed. Measures were made of the number of reference memory errors (entering an arm that was not baited) and working memory errors (entering an arm containing food but previously entered). 7-NI $(50 \mathrm{mg} / \mathrm{kg})$ was suspended in peanut oil at a dose of $50 \mathrm{mg} / \mathrm{kg}$ and administered p.o. $60 \mathrm{~min}$ before each training trial of the radial arm maze test. Control animals were administered with peanut oil in a volume of $1 \mathrm{ml} / \mathrm{kg}$ and subjected to the maze training. The third group of animals was prepared as nontrained control rats, which were kept on a restricted diet as were the other groups of animals, put in the radial arm maze everyday without maze training, and given four food pellets.

Antisense oligonucleotide treatment. Rats were anesthetized with pentobarbital $(50 \mathrm{mg} / \mathrm{kg}$, i.p.) and placed in a stereotaxic apparatus. The infusion cannula was connected to a miniosmotic pump (total capacity, 200 $\mu \mathrm{l}$; Alza, Palo Alto, CA), which was filled with BDNF antisense or sense oligonucleotides, and was implanted into the right ventricle (anterior -0.3 , lateral 1.2, ventral 4.5), according to the atlas of Paxinos and Watson (1982). The pump was placed subcutaneously in the neck of the rat. The BDNF antisense and sense oligonucleotides were continuously inf used into the cerebral ventricle at a dose of $3.6 \mathrm{nmol} / \mathrm{d}$. The infusion of the oligonucleotides was maintained for 2 weeks (flow rate, $0.5 \mu \mathrm{l} / \mathrm{hr}$; Alzet 2002 ) or 4 weeks (flow rate, $0.25 \mu \mathrm{l} / \mathrm{hr}$; Alzet 2004). Phosphothioate oligonucleotides were custom-synthesized at SAWADY technology (Tokyo, Japan) and dissolved in sterile pyrogen-free $0.9 \%$ saline. The sequences of antisense and sense oligonucleotides were $5^{\prime}$-TCTTCCCCTTTTAATGGT-3' and 5'-ACCATTAAAAGGGGAAGA-3', respectively, which correspond to amino acids 114-119 of BDNF (Acheson et al., 1995). The rats were allowed a $3 \mathrm{~d}$ recovery period after the surgery for implantation of the infusion cannula. On day 4 after the start of oligonucleotide inf usion, the rats were subjected to the reference and working memory task, and the test was continued for the indicated time period.

Measurement of locomotor activity and food consumption. Locomotor activity, food consumption, and body weight in rats treated with antisense or sense oligonucleotides of BDNF were measured to see whether motor function and/or motivation were affected by the treatment. Each rat was placed in a locomotor cage $(25 \times 42 \times 20 \mathrm{~cm})$, with photobeams placed 2 $\mathrm{cm}$ above the floor at 1 inch intervals along two sides of the cage (Columbus Instruments). Locomotor activity was measured for $10 \mathrm{~min}$ (Z ou et al. et al., 1998b). After measurement of locomotor activity, rats were individually placed in a home cage, and then 10 baits, which were the same as those used in the radial arm maze test, were provided. The time taken to consume all 10 baits was recorded, with a cutoff time of $180 \mathrm{sec}$ (Zou et al. et al., 1998b).

RT-PCR. Total RNA was extracted from brain tissues by a method previously described (Chamberlain and Burgoyne, 1996) (Qiagen, Tokyo, Japan). The levels of BDNF mRNA in brain tissues were determined by RT-PCR. The mRNA for $\beta$-actin was used as an internal control, to be coamplified with BDNF mRNA. Total RNA $(1 \mu \mathrm{g})$ was converted into cDNA using oligo(dT) 12-18 primer (Life Technologies, Tokyo, Japan) and Moloney murine leukemia virus reverse transcriptase (Life Technologies) in a total reaction volume of $25 \mu \mathrm{l}$ (RT-reaction mixture). PCR was performed using one twenty-fifth of the RT-reaction mixture, $0.5 \mu \mathrm{M}$ of each (forward and reverse) primers, and ReadyToGo PCR Beads (Amersham Pharmacia Biotech, Tokyo, Japan) in a total reaction volume of $25 \mu \mathrm{l}$. The primers used were as follows: BDNF: 5'-CGTGATCGAGGAGCTGTTGG-3' (forward) and 5'-CTGCTTCAGTTGGCCTTTCG-3' (reverse), and $\beta$-actin: $5^{\prime}$-TGCTCGACAACGGCTCCGGCATGT-3' (forward) and 5'CCAGCCAGGTCCAGACGCAGGAT-3' (reverse) (Bova et al., 1998). In a preliminary experiment, the number of PCR cycles and denaturation temperature were tested to ascertain a linear working range for all PCR products. The experimental amplification protocol consisted of a first round at $94^{\circ} \mathrm{C}$ for $5 \mathrm{~min}$ and then 27 cycles of denaturation for $1 \mathrm{~min}$ at $94^{\circ} \mathrm{C}$, annealing for $1 \mathrm{~min}$ at $58^{\circ} \mathrm{C}$, and extension for $2 \mathrm{~min}$ at $72^{\circ} \mathrm{C}$ on a programmable thermal cycler (PCR Thermal Cycler; Takara, Shiga, Japan). The PCR products were visualized by ethidium bromide staining under UV light after electrophoresis on a $1.5 \%$ agarose gel.

$B D N F$ enzyme immunoassay. The BDNF levels were measured by enzyme immunoassay (EIA) as described (Nawa et al., 1995). Briefly, antiBDNF antisera were prepared as described previously and were used as the primary antibody in BDNF detection to coat polystyrene 96-well microtiter plates for EIA. The high-affinity anti-BDNF antibodies were
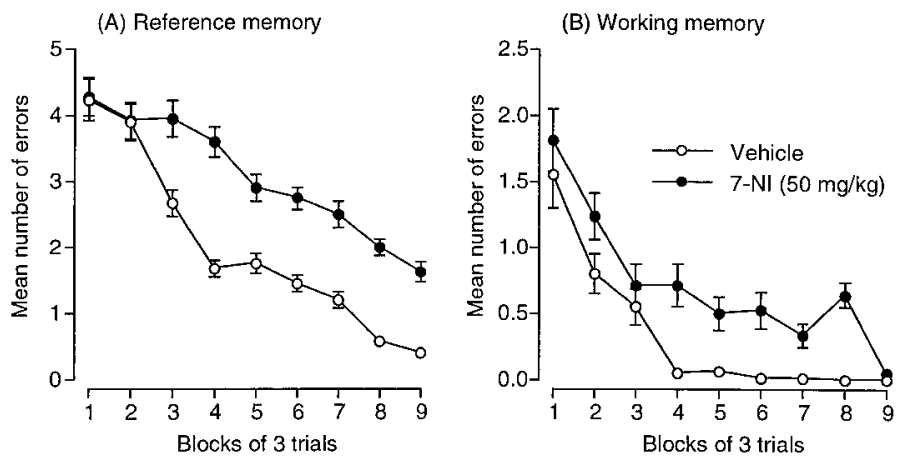

Figure 1. Spatial reference $(A)$ and working $(B)$ memory formation in rats treated with vehicle $(n=20)$ and 7-NI $(n=14)$. 7-NI $(50 \mathrm{mg} / \mathrm{kg})$ was administered p.o. every day $60 \mathrm{~min}$ before each training trial. Each value represents the mean \pm SE. 7-NI significantly impaired reference $(p<$ $0.001)$ and working memory $(p<0.001)$ formation.

biotinylated with NHS-LC-Biotin and used as secondary antibody (Nawa et al., 1995). The EIA detected trace amounts of BDNF ( $>1 \mathrm{pg} / \mathrm{assay})$ and they did not cross-react with 1000-fold excess amounts of other neurotrophins.

Statistical analysis. Results were expressed as the mean \pm SE. The significance of differences was determined by a one-way or two-way ANOVA, followed by Bonferroni's test or the Student-Newman-Keuls test for multigroup comparisons. Student's $t$ test was used for two-group comparisons. An ANOVA with repeated measures was conducted for analyzing data of the radial arm maze. A $p$ value $<0.05$ was regarded as statistically significant.

\section{RESULTS}

To examine whether radial arm maze training affects BDNF mRNA expression in the brain, one group of animals $(n=20)$ was trained for the reference and working memory task for $28 \mathrm{~d}$. The second group $(n=14)$ was treated with a brain NOS inhibitor 7-NI (Babbedge et al., 1993; Moore et al., 1993) every day before the training, which has been previously demonstrated to inhibit the spatial learning in this test (Yamada et al., 1995; Zou et al., 1998a) and to decrease BDNF protein level in the hippocampus (Han et al., 2000). The third group of animals $(n=3)$ was prepared as nontrained rats that were kept on a restricted diet like the other groups of animals, put on the radial arm maze everyday without maze training, and given four food pellets on the maze.

Figure 1 shows the alterations of performance in rats produced by repeated daily training in the reference and working memory task. An ANOVA with repeated measures revealed significant effects of group $\left(F_{(1,32)}=72.336 ; p<0.0001\right)$, trial $\left(F_{(8,256)}=\right.$ $68.412 ; p<0.0001)$, and group by trial interaction $\left(F_{(8,256)} \stackrel{2}{=} 4.761\right.$; $p<0.0001)$ in reference memory (Fig. $1 A$ ). In working memory, there were significant effects on group $\left(F_{(1,32)}=19.987 ; p<0.0001\right)$ and trial $\left(F_{(8,256)}=33.196 ; p<0.0001\right)$, but not group by trial interaction $\left(F_{(8,256)}=1.343 ; p=0.2225\right)$ (Fig. $\left.1 B\right)$. These results indicate that 7-NI inhibits both spatial reference memory and working memory formation.

Three groups of rats were killed either immediately, 15, or 30 min after the maze training on day 28. Because the prefrontal cortex and hippocampus are involved in reference and working memory (Olton et al., 1979; Kesner et al., 1987; Chiba et al., 1997; Porter et al., 2000), BDNF mRNA levels in the frontal cortex, including anterior cingulate cortex and motor area of frontoparietal cortex, and the whole hippocampus were measured by RT-PCR (Fig. $2 A, C$ ). There was no difference in the BDNF mRNA level before and after the taking of the four food pellets in the nontrained rats, suggesting that food consumption per se has no effect on BDNF mRNA level (data not shown).

A two-way ANOVA of the data in the hippocampus of the trained rats with or without 7-NI treatment revealed a significant effect of 7-NI treatment $\left(F_{(1,28)}=49.618 ; p<0.0001\right)$, time $\left(F_{(2,28)}\right.$ $=5.054 ; p=0.0134)$, and treatment by time interaction $\left(F_{(2,28)}=\right.$ $10.436 ; p=0.004$ ) (Fig. $2 B$ ). A one-way ANOVA of the vehicletreated trained rats including the control animals revealed a signif- 


\section{(A) Hippocampus}

Figure 2. Changes in BDNF mRNA expression in the hippocampus and frontal cortex of rats associated with spatial memory formation. Rats were trained for the reference and working memory task for $28 \mathrm{~d}$. 7-NI was administered every day $60 \mathrm{~min}$ before each training trial. Animals were killed immediately, 15 , or $30 \mathrm{~min}$ after the last training. The levels of BDNF and $\beta$-actin were measured by RTPCR. Representative gel patterns showing BDNF and $\beta$-action cDNA bands at different times after training in the hippocampus $(A)$ and frontal cortex $(C)$. The quantitative results of RT-PCR in the hippocampus $(B)$ and frontal cortex $(D)$. The number in parentheses shows the number of animals. The BDNF mRNA level was normalized with the $\beta$-action mRNA level. Each value represents the mean \pm SE. $* * * p<0.001$ versus immediately after the training $(0 \mathrm{~min})$. $\# \# \# p<0.001$ versus corresponding vehicle-treated rats.

(B)

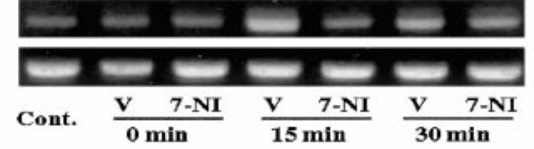

(C) Frontal cortex

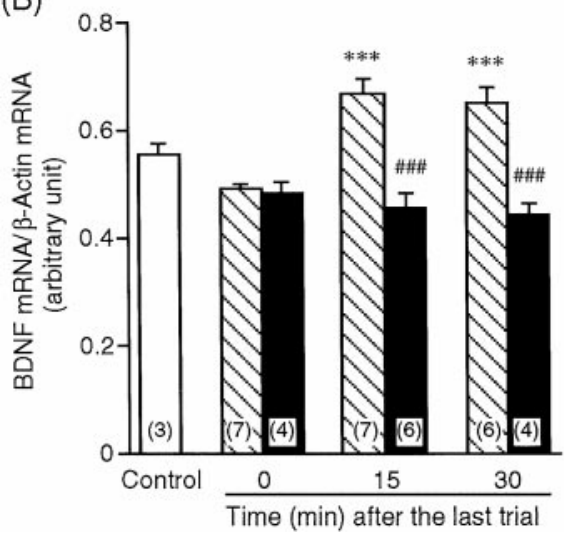

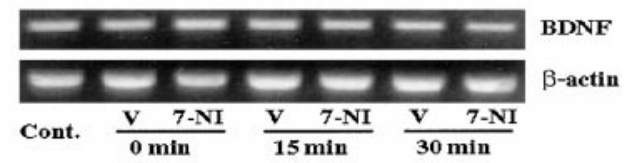

(D)

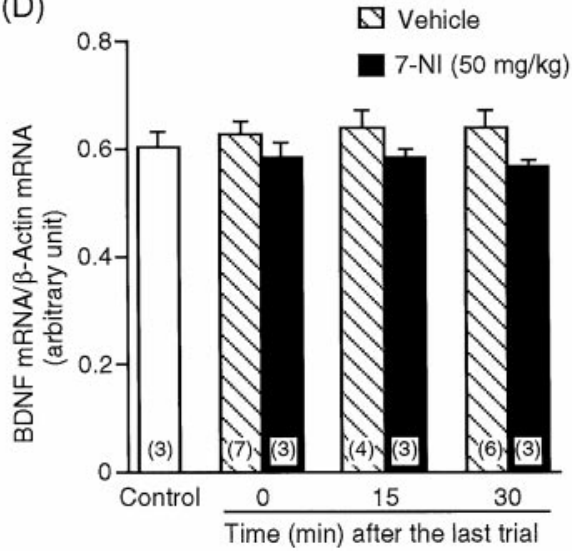

icant group effect $\left(F_{(3,19)}=13.736 ; p<0.0001\right)$. Post hoc analysis with Bonferroni's test indicated that the level of BDNF mRNA in the hippocampus was significantly increased 15 and 30 min after the training trial compared with the level immediately after the training trial $(p<0.001)$ (Fig. $2 B)$. When spatial learning was inhibited by treatment with 7-NI, the changes in BDNF mRNA expression were not observed $\left(F_{(3,13)}=2.8555 ; p=0.0780\right)$. There was a significant difference (Student's $t$ test, $p<0.001$ ) in BDNF mRNA levels between vehicle- and 7-NI-treated rats 15 and 30 min, but not immediately after the last training trial (Fig. 2B). A significant correlation was found between the number of reference memory errors on day 28 and BDNF mRNA levels in the hippocampus at $15(r=-0.695 ; p=0.0067)$ and $30 \mathrm{~min}(r=-0.693$; $p=0.024)$, but not immediately $(r=0.035 ; p=0.921)$, after the training trial. There was no correlation between the number of working memory errors on day 28 and BDNF mRNA levels in the hippocampus at any time points examined. In the frontal cortex, a two-way ANOVA revealed a small but significant effect of 7-NI treatment $\left(F_{(1,20)}=4.804 ; p=0.0404\right)$, although no significant effects were observed in time $\left(F_{(2,20)}=0.038 ; p=0.9626\right)$ and treatment by time interaction $\left(F_{(2,20)}=0.102 ; p=0.9034\right)$ (Fig. $\left.2 D\right)$.

These results suggest that spatial memory formation is associated with an increase in BDNF mRNA in the hippocampus, a brain structure being involved in spatial learning and memory in the radial arm maze test (Olton et al., 1979). However, it is still unclear whether the alteration is the cause or the effect of spatial learning. To clarify the causal relation between the changes in BDNF levels and spatial learning, rats first received surgery for continuous intracerebroventricular infusion of antisense BDNF oligonucleotide, and after a $4 \mathrm{~d}$ recovery period they were subjected to the spatial learning test.

Figure 3 illustrates the maze performance in nonoperated control rats and the rats that received a continuous intracerebroventricular infusion of antisense or sense BDNF oligonucleotide. An ANOVA with repeated measures of the data from the three groups revealed significant effects of group $\left(F_{(2,16)}=193.410 ; p<0.0001\right)$, trial $\left(F_{(6,96)}=50.681 ; p<0.0001\right)$, and group by trial interaction $\left(F_{(12,96)}=6.172 ; p<0.0001\right)$ on the reference memory formation (Fig. 3A). Post hoc analysis with Bonferroni's test indicated that antisense BDNF oligonucleotide treatment significantly inhibited spatial reference memory formation $(p<0.001)$ (Fig. $3 A)$.

In the working memory formation, an ANOVA with repeated measures indicated significant effects of group $\left(F_{(2,16)}=38.368\right.$; $p<0.0001)$ and trial $\left(F_{(6,96)}=15.435 ; p<0.001\right)$, but not group by trial interaction $\left(F_{(12,96)}=1.227 ; p=0.2761\right)$ (Fig. $\left.3 B\right)$. Post hoc
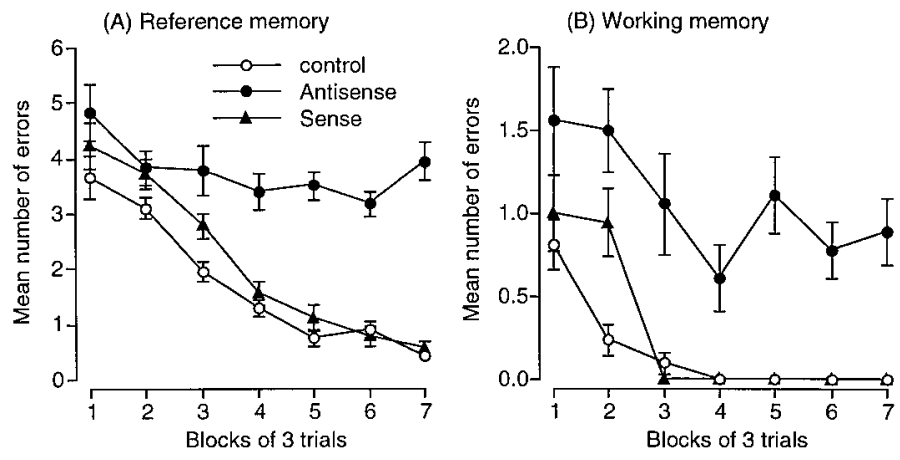

Figure 3. Spatial reference $(A)$ and working $(B)$ memory formation in nonoperated control rats $(n=7)$ and rats that were continuously infused with BDNF antisense $(n=6)$ and sense oligonucleotides $(n=6)$ into the cerebral ventricle. The maze training was started $4 \mathrm{~d}$ after the start of continuous intracerebroventricular infusion of the oligonucleotide. Each value represents the mean $\pm \mathrm{SE}$. Antisense BDNF treatment significantly impaired reference $(p<0.001)$ and working memory formation $(p<$ $0.001)$.

analysis with Bonferroni's test revealed that antisense BDNF oligonucleotide treatment significantly inhibited spatial working memory formation $(p<0.001)$, although the sense oligonucleotide treatment had no effect (Fig. $3 B$ ).

We also examined the effects of BDNF antisense oligonucleotide on locomotor function and appetite, which affect performance in the radial arm maze test. There were no differences in locomotor activity, food consumption, and body weight between the antisense and sense oligonucleotide-treated rats $(p>0.05$, Student's $t$ test $)$ (Fig. 4A-C). Thus, it is unlikely that the impairment of the maze performance in rats treated with antisense BDNF oligonucleotide is a secondary effect of the motor dysfunction or an altered motivational state.

To confirm the effect of continuous intracerebroventricular infusion of antisense BDNF oligonucleotide on BDNF synthesis, rats were killed on day 22, and BDNF mRNA and protein levels were determined (Fig. 5). A one-way ANOVA revealed a significant group effect in BDNF protein $\left(F_{(2,13)}=5.6356 ; p<0.05\right)$ and mRNA levels $\left(F_{(2,9)}=26.218 ; p<0.001\right)$. Post hoc analyses revealed that both BDNF protein (Fig. $5 A$ ) and mRNA (Fig. $5 B$ ) levels in the hippocampus of the antisense oligonucleotide-treated rats were significantly lower than those in nonoperated control $(p<0.05)$. Neither BDNF protein nor mRNA levels were affected by treatment with the sense oligonucleotide. 
(A) Locomotor activity
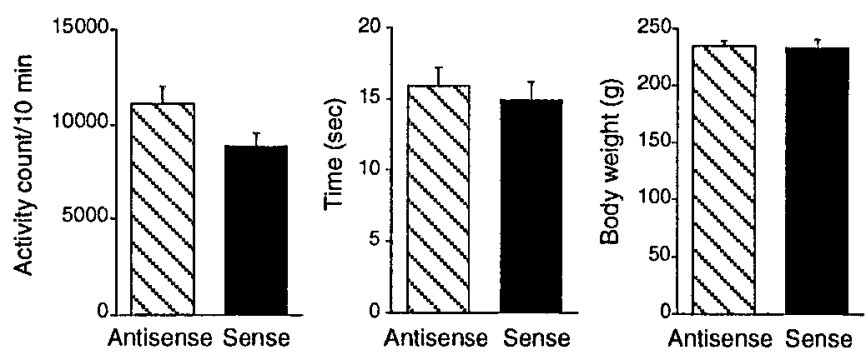

Figure 4. Effects of continuous infusion of BDNF antisense $(n=6)$ and sense oligonucleotides $(n=6)$ into the cerebral ventricle on locomotor activity, food consumption, and body weight. Rats were continuously infused with BDNF antisense or sense oligonucleotide into the cerebral ventricle and were subjected to the radial maze test for $21 \mathrm{~d}$. Locomotor activity $(A)$, food consumption $(B)$, and body weight $(C)$ were measured on the day after the last training. Each value represents the mean $\pm \mathrm{SE}$.
(A) BDNF protein

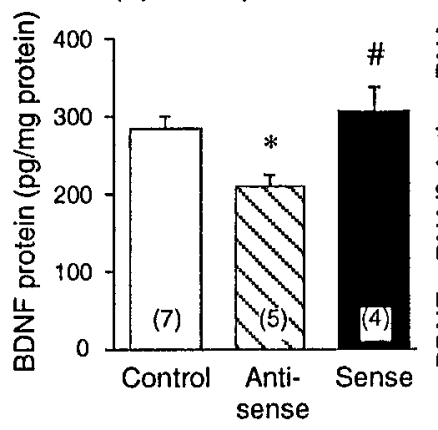

(B) BDNF MRNA

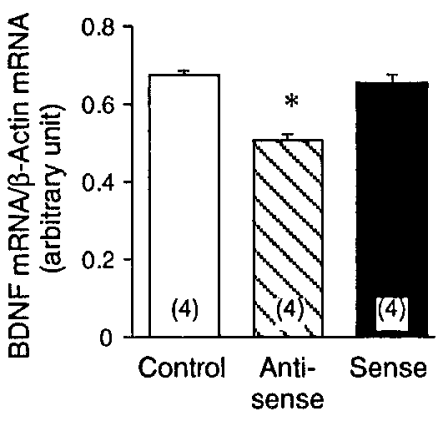

Figure 5. Effects of continuous infusion of BDNF antisense and sense oligonucleotides into the cerebral ventricle on BDNF protein $(A)$ and mRNA $(B)$ levels in the hippocampus. Rats were continuously infused with BDNF antisense or sense oligonucleotide into the cerebral ventricle and were subjected to the radial maze test for $21 \mathrm{~d}$. The rats treated with antisense or sense BDNF oligonucleotide and nontrained control rats were killed on the day after the last training for the measurement of BDNF protein $(A)$ and mRNA $(B)$ levels. The number in parentheses shows the number of animals. Each value represents the mean $\pm \mathrm{SE}$. ${ }^{*} p<0.05$ versus control. \#p $<0.05$ versus antisense-treated group.

Finally, to investigate the role of BDNF in memory retention and/or recall, antisense BDNF oligonucleotide was infused in rats that had been trained for the reference and working memory task for $28 \mathrm{~d}$. The rats underwent surgery for continuous intracerebroventricular infusion of either antisense or sense BDNF oligonucleotide on day 29. After a 4 d recovery period, they were subjected to the same reference and working memory task.

Figure 6 shows the effects of antisense BDNF treatment on previously acquired spatial memory. An ANOVA with repeated measures of the data after the surgery revealed a significant effect of group $\left(F_{(1,19)}=61.035 ; p<0.0001\right)$, but not trial $\left(F_{(5,95)}=\right.$ $0.289 ; p=0.9178)$ and group by trial interaction $\left(F_{(5,95)}=0.303\right.$; $p=0.9100$ ) on reference memory (Fig. 6A). There were also significant effects of group $\left(F_{(1,19)}=34.410 ; p<0.0001\right)$, but not trial $\left(F_{(5,95)}=0.127 ; p=0.9859\right)$ and group by trial interaction

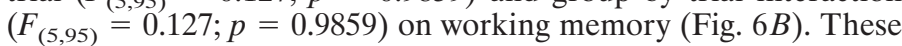
results indicated that the number of both reference and working memory errors was significantly increased by treatment with antisense BDNF oligonucleotide compared with the sense oligonucleotide.

\section{DISCUSSION}

Memory formation is considered to involve both short-term changes in electrical properties and long-term structural alterations in synapses. Short-term changes may include LTP (Barnes, 1995) and LTD (Ito, 1986), whereas long-term morphological alterations may involve synaptogenesis and neuropil growth (Burns and Au-
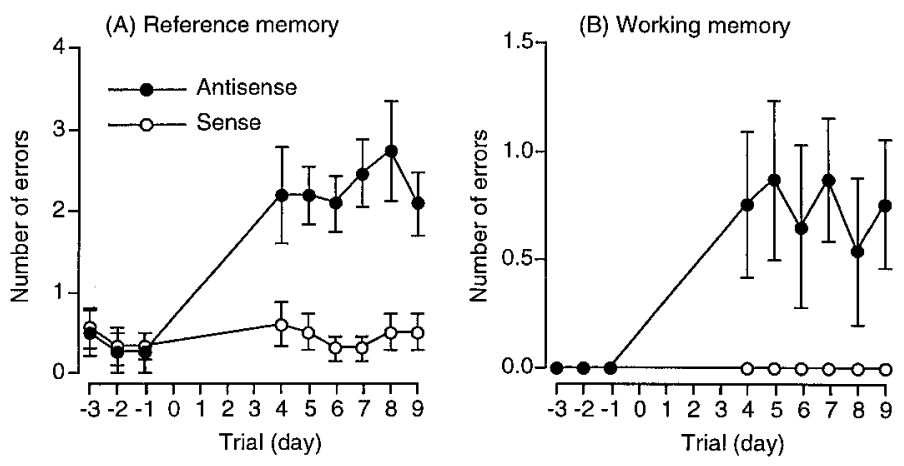

Figure 6. Effects of continuous infusion of BDNF antisense and sense oligonucleotide into the cerebral ventricle on spatial reference $(A)$ and working $(B)$ memory retention and/or recall in rats which had previously acquired the spatial reference and working memory. Rats were first trained for the reference and working memory task for $28 \mathrm{~d}$ and then received a surgical operation for the continuous intracerebroventricular infusion of BDNF antisense $(n=11)$ or sense oligonucleotide $(n=10)$. The radial maze test was started $4 \mathrm{~d}$ after the start of oligonucleotide treatment. Each value represents the mean $\pm \mathrm{SE}$. Antisense BDNF treatment significantly increased the number of reference $(p<0.0001)$ and working memory errors $(p<0.0001)$.

gustine, 1995; Edwards, 1995). Because BDNF significantly modulates both forms of synaptic changes, it has been suggested to play a role in neuronal plasticity such as learning and memory (Lo, 1995; Thoenen, 1995).

We demonstrated in the present study that spatial memory formation is associated with an increase in BDNF mRNA level in the hippocampus in the radial arm maze test. The increase in BDNF mRNA was not observed when learning was inhibited by treatment with a brain NOS inhibitor, 7-NI (Babbedge et al., 1993; Moore et al., 1993). The continuous intracerebroventricular infusion of antisense BDNF oligonucleotide resulted in a severe impairment in reference and working memory formation, which was accompanied by a reduction of BDNF mRNA and protein levels in the hippocampus. Furthermore, the antisense BDNF treatment disrupted previously formed spatial memory. Our findings suggest an essential role for BDNF in the acquisition, as well as retention and/or recall, of spatial memory.

With regard to a role for BDNF in memory formation, it has been demonstrated, by using nuclease protection assay and in situ hybridization, that the level of BDNF mRNA was elevated in the hippocampus but not cerebellum, striatum, frontal, and middle or caudal neocortex in the learning group compared with yoked and sedentary controls after 3 and $6 \mathrm{~d}$ of training in the water maze (Kesslak et al., 1998). It is also reported, using a RT-PCR method, that the BDNF mRNA level in the dentate gyrus of the hippocampus was significantly increased in rats showing good retention compared with the poor retention control animals (Ma et al., 1998). All these studies, including our own, suggest that learning is associated with an alteration of BDNF mRNA in the hippocampus in spite of differences in levels of stress and the types of motivation involved in the behavioral tasks used. It should be noted, however, that there was no apparent increase in BDNF mRNA levels immediately after the training trial on day 28 . The results suggest that previous training for $27 \mathrm{~d}$ has no residual effect on BDNF mRNA levels, and the levels may get turned over between training trial days. Therefore, it remains to be determined how such alterations of BDNF mRNA expression after training trial contribute to spatial reference and working memory formation.

We have used RT-PCR instead of Northern blotting or nuclease protection assay to quantify BDNF mRNA, under conditions that PCR cycles were within a linear working range for all PCR products, and the levels of $\beta$-actin mRNA were determined as internal controls. Further experiments should be undertaken with Northern blot analysis to determine the levels and in situ hybridization histochemistry to map the distribution of BDNF mRNA expression. 
The paucity of agents that can selectively and potently block the synthesis of BDNF or its receptor trkB has led to investigations into the role of BDNF in learning and memory using BDNF and trkB mutant mice. Because most mice deficient in BDNF (Ernfors et al., 1994) and trkB (Klein et al., 1993) die after birth, behavioral experiments had so far been limited to the heterozygous mutant mice. The results are controversial. One study has shown that heterozygous BDNF mutant mice show a moderate but significant impairment of water maze learning without any effect on memory retention (Linnarsson et al., 1997), whereas another study has failed to detect deficits of performance in the water maze test (Montkowski and Holsboer, 1997). Recently, Minichiello et al. (1999) generated conditionally gene targeted mice in which the knock-out of the trkB gene is restricted to the forebrain and occurs only during postnatal development (trkB-CRE mutant mice), and they analyzed their ability to learn and memorize. The trkB-CRE mutant mice completely failed the more stressful water maze test, partly failed the eight-arm maze test, but succeeded in simple passive avoidance learning, suggesting a role for trkB receptor signaling in complex learning. The results also implied that procedural long-term memory is relatively spared, whereas short-term plasticity within the hippocampus is impaired in the trkB-CRE mutant mice (Minichiello et al., 1999).

Our results clearly indicate that BDNF plays an essential role in both reference and working memory. Reference memory refers to memory for information that remains constant over repeated trials and is, therefore, trial-independent. Working memory refers to memory in which the information to be remembered changes in repeated trials, and thereby, is trial-dependent (Olton et al., 1979). Both hippocampus and cerebral cortex have been suggested to contribute to reference and working memory (Kesner et al., 1987; Jarrard, 1993; Durkin, 1994), and these brain areas contain relatively high levels of BDNF proteins (Nawa et al., 1995; KatohSemba et al., 1997). Although learning-associated change in the BDNF mRNA level was observed only in the hippocampus, not in the frontal cortex, it remains to be determined which brain structure or structures are the site or sites of action of BDNF in spatial reference and working memory. A direct focal infusion of antisense BDNF oligonucleotide into the hippocampus or the frontal cortex may allow a more detailed dissection of the role for BDNF in reference and working memory.

The impairment of BDNF synthesis induced by antisense BDNF treatment resulted in an impairment of memory retention and/or recall, as well as memory formation, in the radial arm maze test. There was no difference, however, in memory retention between the BDNF mutant and wild-type mice, as assessed by performance in a spatial probe test immediately and 4 weeks after training for the water maze (Linnarsson et al., 1997). The reasons for the discrepancy between the two studies are unclear. BDNF is involved in the modulation of synaptic transmission such as cholinergic and glutamatergic neurotransmission, and produces a fast physiological response, similar to those observed in classical neurotransmitters (Berninger and Poo, 1996). These effects may explain the impairment of memory retention induced by antisense BDNF treatment because inhibition of cholinergic and glutamatergic neurotransmission impairs memory retention in rats (Nabeshima, 1993; Yamada et al., 1996a; Zou et al., 1998b, 1999). The BDNF mutant mice, on the other hand, failed to show such impairment because of possible compensations by neural systems for the gene mutation.

It is important to establish the earliest time point at which BDNF antisense treatment is effective in downregulating BDNF mRNA and protein. Although we did not perform such experiments, the last experiment indicated that the antisense inf usion for $4 \mathrm{~d}$ was sufficient to disrupt spatial memory (Fig. 6). Therefore, we consider that a relatively short-term intracerebroventricular infusion (at least $4 \mathrm{~d}$ ) of antisense BDNF oligonucleotide may be effective in downregulating BDNF mRNA and protein under our experimental condition.

There is evidence that NO is involved in the mechanisms of synaptic plasticity, including LTP (Bliss and Collingridge, 1993; Garthwaite and Boulton, 1995; Son et al., 1996), LTD (Shibuki and Okada, 1991), and learning and memory in vivo (Yamada et al., 1995, 1996a,b; Zou et al., 1998a). Thus, it appears that BDNF and NO have similar effects on synaptic activities and learning and memory processes. Mutual regulation of these two molecules in their synthesis has been demonstrated in vitro and in vivo (Xiong et al., 1999). In the present study, 7-NI inhibited spatial memory formation, which was associated with a failure of alteration of BDNF mRNA induced by the maze training. These effects of 7-N I are consistent with our previous findings that 7-NI inhibits pentylenetetrazole-induced kindling, a form of synaptic plasticity that was accompanied by prevention of the kindling-induced increase in BDNF protein levels in the hippocampus (Han et al., 2000). It should be elucidated why 7-NI suppressed BDNF mRNA expression at longer intervals (15 and $30 \mathrm{~min}$ ), but not immediately, after learning.

In summary, this study, in which BDNF synthesis has been diminished by the continuous intracerebroventricular infusion of BDNF antisense oligonucleotide, suggests an essential role for BDNF in spatial memory formation as well as memory retention and/or recall. Further work, in which infusion of antisense oligonucleotide will be restricted to certain brain structures such as the hippocampus, will shed light on the mechanism and on neuronal pathways that require BDNF/trkB signaling in learning and memory processes.

\section{REFERENCES}

Acheson A, Conover JC, Fandl JP, DeChiare TM, Russell M, Thadani A, Squinto SP, Yancopoulos GD, Lindsay RM (1995) A BDNF autocrine loop in adult sensory neurons prevents cell death. Nature 374:450-453.

Babbedge RC, Bland-Ward PA, Hart SL, Moore PK (1993) Inhibition of rat cerebellar nitric oxide synthase by 7-nitroindazole and related substituted indazoles. Br J Pharmacol 110:225-228.

Barde YA, Edgar D, Thoenen H (1982) Purification of a new neurotrophic factor from mammalian brain. EMBO J 1:549-53.

Barnes CA (1995) Involvement of LTP in memory: are we "searching under the street light"? Neuron 15:751-754.

Berninger B, Poo MM (1996) Fast actions of neurotrophic factors. Curr Opin Neurobiol 6:324-330.

Bliss TV, Collingridge GL (1993) A synaptic model of memory: long-term potentiation in the hippocampus. Nature 361:31-39.

Bova R, Micheli MR, Qualadrucci P, Zucconi GG (1998) BDNF and trkB mRNAs oscillate in rat brain during the light-dark cycle. Mol Brain Res 57:321-324.

Burns ME, Augustine GJ (1995) Synaptic structure and function: dynamic organization yields architectural precision. Cell 83:187-194.

Cabelli R, Hohn A, Shatz CJ (1995) Inhibition of ocular dominance column formation by infusion of NT-4/5 or BDNF. Science 267:1662-1666.

Chamberlain LH, Burgoyne RD (1996) Identification of a novel cysteine string protein variant and expression of cysteine string proteins in nonneuronal cells. J Biol Chem 271:7320-7323.

Chiba AA, Kesner RP, Gibson CJ (1997) Memory for temporal order of new and familiar spatial location sequences: role of the medial prefrontal cortex. Learn Mem 4:311-317.

Durkin TP (1994) Spatial working memory over long retention intervals: dependence of sustained cholinergic activation in the septohippocampal or nucleus basalis magnocellularis-cortical pathways? Neuroscience 62:681-693.

Edwards FA (1995) Anatomy and electrophysiology of fast central synapses lead to a structural model for long-term potentiation. Physiol Rev 75:759-787.

Ernfors P, Bengzon J, Kokaia Z, Persson H, Lindvall O (1991) Increased levels of messenger RNAs for neurotrophic factors in the brain during kindling epileptogenesis. Neuron 7:165-176.

Ernfors P, Lee K-F, Jaenisch R (1994) Mice lacking brain-derived neurotrophic factor develop with sensory deficits. Nature 368:147-150.

Figurov A, Pozzo-Miller LD, Olafsson P, Wang T, Lu B (1996) Regulation of synaptic responses to high-frequency stimulation and LTP by neurotrophins in the hippocampus. Nature 381:706-709.

Garthwaite J, Boulton CL (1995) Nitric oxide signaling in the central nervous system. Annu Rev Physiol 57:683-706.

Han D, Yamada K, Senzaki K, Xiong H, Nawa H, Nabeshima T (2000) Involvement of nitric oxide in pentylenetetrazol-induced kindling in rats. J Neurochem 74:792-798.

Ito M (1986) Long-term depression as a memory process in the cerebellum. Neurosci Res 3:531-539.

Jarrard LE (1993) On the role of the hippocampus in learning and memory in the rat. Behav Neural Biol 60:9-26. 
Kang H, Schuman M (1995) Long-lasting neurotrophin-induced enhancement of synaptic transmission in the adult hippocampus. Science 267:1658-1662.

Kang H, Schuman M (1996) A requirement for local protein synthesis in neurotrophin-induced hippocampal synaptic plasticity. Science 273:1402-1406.

Katoh-Semba R, Takeuchi IK, Semba R, Kato K (1997) Distribution of brain-derived neurotrophic factor in rats and its changes with development in the brain. J Neurochem 69:34-42.

Kesner RP, Dimattia BV, Crutcher KA (1987) Evidence for neocortical involvement in reference memory. Behav Neural Biol 47:40-53.

Kesslak JP, So V, Choi J, Cotman CW, Gomez-Pinilla F (1998) Learning upregulates brain-derived neurotrophic factor messenger ribonucleic acid: a mechanism to facilitate encoding and circuit maintenance? Behav Neurosci 112:1012-1019.

Kinoshita S, Yasuda H, Taniguchi N, Katoh-Semba R, Hatanaka H, Tsumoto T (1999) Brain-derived neurotrophic factor prevents lowfrequency inputs from inducing long-term depression in the developing visual cortex. J Neurosci 19:2122-2130.

Klein R, Smeyne RJ, Wurst W, Long LK, Auerbach BA, Joyner AL, Barbacid M (1993) Targeted disruption of the trkB neurotrophin receptor gene results in nervous system lesions and neonatal death. Cell 75:113-122.

Knipper M, Berzaghi MP, Blochl A, Breer H, Thoenen H, Lindholm D (1994) Positive feedback between acetylcholine and the neurotrophic factor in the rat hippocampus. Eur J Neurosci 8:668-671.

Knüsel B, Winslow JW, Rosenthal A, Burton LE, Seid DP, Nikolics K, Hefti F (1991) Promotion of central cholinergic and dopaminergic neuron differentiation by brain-derived neurotrophic factor but not neurotrophin-3. Proc Natl Acad Sci USA 88:961-965.

Korte M, Carroll P, Wolf E, Brem G, Thoenen H, Bohnoeffer T (1995) Hippocampal long-term potentiation is impaired in mice lacking brainderived neurotrophic factor. Proc Natl Acad Sci USA 92:8856-8860.

Leibrock J, Lottspeich F, Hohn A, Hofer M, Hengerer B, Masiakowski P, Thoenen H, Barde Y-A (1989) Molecular cloning and expression of brain-derived neurotrophic factor. Nature 341:149-152.

Levine ES, Dreyfus CF, Black IB, Plummer MR (1995) Brain-derived neurotrophic factor rapidly enhances synaptic transmission in hippocampal neurons via postsynaptic tyrosine kinase receptors. Proc Natl Acad Sci USA 92:8074-8077.

Lessmann V, Gottmann K, Heumann R (1994) BDNF and NT-4/5 enhance glutamatergic synaptic transmission in cultured hippocampal neurons. NeuroReport 6:21-25.

Lin S-Y, Wu K, Levine ES, Mount HTJ, Suen P-C, Black IB (1998) BDNF acutely increases tyrosine phosphorylation of the NMDA receptor subunit $2 \mathrm{~B}$ in cortical and hippocampal postsynaptic densities. Mol Brain Res 55:20-27.

Linnarsson S, Bjuörklund A, Ernfors P (1997) Learning deficit in BDNF mutant mice. Eur J Neurosci 9:2581-2587.

Lohof AM, Ip NY, Poo MM (1993) Potentiation of developing neuromuscular synapses by the neurotrophins NT-3 and BDNF. Nature 363:350-353.

Lo DC (1995) Neurotrophic factors and synaptic plasticity. Neuron 15:979-981.

Ma YL, Wang HL, Wu HC, Wei CL, Lee EHY (1998) Brain-derived neurotrophic factor antisense oligonucleotide impairs memory retention and inhibits long-term potentiation in rats. Neuroscience 82:957-967.

Minichiello L, Korte M, Wolfer D, Kühn R, Unsicker K, Cestari V, Rossi-Arnaud C, Lipp H-P, Bonhoeffer T, Klein R (1999) Essential role for trkB receptors in hippocampus-mediated learning. Neuron 24:401-414.

McAllister AK, Lo DC, Katz LC (1995) Neurotrophins regulate dendritic growth in developing visual cortex. Neuron 4:791-803.

Montkowski A, Holsboer F (1997) Intact spatial learning and memory in transgenic mice with reduced BDNF. NeuroReport 8:779-782.

Moore PK, Babbedge RC, Wallace P, Gaffen ZA, Hart SL (1993) Characterization of the novel nitric oxide synthase inhibitor 7-nitro indazole and related indazoles: antinociceptive and cardiovascular effects. $\mathrm{Br} \mathrm{J}$ Pharmacol 110:219-224.

Mu J-S, Li W-P, Yao Z-B, Zhou X-F (1999) Deprivation of endogenous brain-derived neurotrophic factor results in impairment of spatial learning and memory in adult rats. Brain Res 835:259-265.

Nabeshima T (1993) Behavioral aspects of cholinergic transmission: a role of basal forebrain cholinergic system in learning and memory. Prog Brain Res 98:405-411.

Nawa H, Carnahan J, Gall C (1995) BDNF protein measured by a novel enzyme immunoassay in normal brain and after seizure: partial disagreement with mRNA levels. Eur J Neurosci 7:1527-1535.

Nibuya M, Morinobu S, Duman RS (1995) Regulation of BDNF and trkB mRNA in rat brain by chronic electroconvulsive seizure and antidepressant drug treatments. J Neurosci 15:7539-7547.

Nonner D, Barrett EF, Barrett JN (1996) Neurotrophin effects on survival and expression of cholinergic properties in cultured rat septal neurons under normal and stress conditions. J Neurosci 16:6665-75.

Olton DS, Becker JT, Handelmann GE (1979) Hippocampus, space, and memory. Behav Brain Sci 2:313-365.

Patterson SL, Grover LM, Schwartzkroin PA, Bothwell M (1992) Neurotrophin expression in rat hippocampal slices: a stimulus paradigm inducing LTP in CA1 evokes increases in BDNF and NT-3 mRNAs. Neuron 9:1081-1088.

Patterson SL, Abel T, Deuel TAS, Martin KC, Rose JC, Kandel ER (1996) Recombinant BDNF rescues deficits in basal synaptic transmission and hippocampal LTP in BDNF knockout mice. Neuron 16:1137-1145.

Paxinos G, Watson C (1982) The rat brain in stereotaxic coordinates. New York: Academic.

Porter MC, Burk JA, Mair RG (2000) A comparison of the effects of hippocampal or prefrontal cortical lesions on three versions of delayed non-matching-to-sample based on positional or spatial cues. Behav Brain Res 109:69-81.

Shibuki K, Okada D (1991) Endogenous nitric oxide release required for long-term synaptic depression in the cerebellum. Nature 349:326-328.

Smith MA, Makino S, Kvetnansky R, Post RM (1995) Stress and glucocorticoids affect the expression of brain-derived neurotrophic factor and neurotrophin-3 mRNAs in the hippocampus. J Neurosci 15:1768-1777.

Son H, Hawkins RD, Martin K, Kiebler M, Huang PL, Fishman MC, Kandel ER (1996) Long-term potentiation is reduced in mice that are doubly mutant in endothelial and neuronal nitric oxide synthase. Cell 87:1015-1023.

Suen P-C, Wu K, Levine ES, Mount HTJ, Xu J-L, Lin S-Y (1997) Brainderived neurotrophic factor rapidly enhances phosphorylation of the postsynaptic $N$-methyl-D-aspartate receptor subunit 1 . Proc Natl Acad Sci USA 94:8191-8195.

Thoenen H (1995) Neurotrophins and neuronal plasticity. Science 270:593-598.

Ventimiglia R, Mather PE, Jones BE, Lindsay RM (1995) The neurotrophins BDNF, NT-3 and NT-4/5 promote survival and morphological and biochemical differentiation of striatal neurons in vitro. Eur $\mathrm{J}$ Neurosci 7:213-22.

Xiong H, Yamada K, Han D, Nabeshima T, Enikolopov G, Carnahan J, Nawa H (1999) Mutual regulation between the intercellular messengers nitric oxide and brain-derived neurotrophic factor in rodent neocortical neurons. Eur J Neurosci 11:1567-1576.

Yamada K, Nabeshima T (1998) Nitric oxide and cyclic GMP signaling pathway in learning and memory processes. Curr Top Pharmacol 4:77-86.

Yamada K, Noda Y, Nakayama S, Komori Y, Sugihara H, Hasegawa T, Nabeshima T (1995) Role of nitric oxide in learning and memory and in monoamine metabolism in the rat brain. Br J Pharmacol 115:852-858.

Yamada K, Noda Y, Hasegawa T, Komori Y, Nikai T, Sugihara H, Nabeshima T (1996a) The role of nitric oxide in dizocilpine-induced impairment of spontaneous alternation behavior in mice. J Pharmacol Exp Ther 276:460-466.

Yamada K, Hiramatsu M, Noda Y, Mamiya T, Murai M, Kameyama T, Komori Y, Nikai T, Sugihara H, Nabeshima T (1996b) Role of nitric oxide and cyclic GMP in the dizocilpine-induced impairment of spontaneous alternation behavior in mice. Neuroscience 74:365-374.

Zou L-B, Yamada K, Tanaka K, Kameyama T, Nabeshima T (1998a) Nitric oxide synthase inhibitors impair reference memory formation in a radial arm maze task in rats. Neuropharmacology 37:323-330.

Zou L-B, Yamada K, Nabeshima T (1998b) $\sigma$ receptor ligands (+)SKF10,047 and SA4503 improve dizocilpine-induced spatial memory deficits in rats. Eur J Pharmacol 355:1-10.

Zou L-B, Yamada K, Sasa M, Nabeshima T (1999) Two phases of behavioral plasticity in rats following unilateral excitotoxic lesion of the hippocampus. Neuroscience 92:819-826. 